\title{
DESIGN AND OPTIMIZATION OF TOLMETIN SODIUM MICROSPHERES PREPARED BY EMULSIFICATION-INTERNAL GELATION USING RESPONSE SURFACE METHODOLOGY
}

\author{
Mahmoud Mohamed Ahmed Elsayed* \\ Department of Pharmaceutics and Industrial Pharmacy, Faculty of Pharmacy, Al-Azhar \\ University, Assiut branch, Assiut, Egypt
}

\begin{abstract}
In a trial to delay the release rate of tolmetin sodium from alginate coated microspheres, the use of a copolymer was suggested. Mixtures of polymers can have a significant property than that of individual polymer to achieve controlled release microspheres. A $3^{2}$ factorial design was employed to produce controlled release microspheres of tolmetin sodium in sodium alginate and ethyl cellulose copolymers by emulsification internal gelation methodology. The effect of critical formulation variables namely, drug to polymer ratio(D:P ratio) and speed of rotation on drug loading efficiency (LE), drug release at the end of 2 hours $\left(\operatorname{Rel}_{2}\right)$ and drug release at the end of 8 hours $\left(\operatorname{Rel}_{8}\right)$ were analyzed using response surface methodology. The parameters were evaluated using the F test and mathematical models containing only the significant terms were generated for each parameter using multiple linear regression analysis and analysis of variance. The produced microspheres were spherical in shape with large pores at D:P ratio 1:2 and small pores at drug to polymer ratio 1:4. Differential scanning calorimetry confirmed the stable character of tolmetin sodium in the drug loaded microspheres and revealed crystalinity form. Both formulation variables studied exerted a significant influence $(p<0.05)$ on the drug release whereas the speed emerged as a lone factor significantly influencing the drug loading efficiency. Increasing the D: P ratio decreases the release of the drug after two and eight hours. The increase of speed results in an increase of drug release after two and eight hours. The drug release from the microspheres followed zero order kinetics.
\end{abstract}

\section{INTRODUCTION}

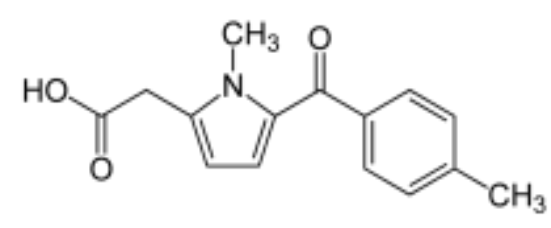

[1-methyl-5-(4-methylbenzoyl)-1H-pyrrol-2-yl] acetic acid

Tolmetin sodium is an effective anti-inflammatory and analgesic drug in clinical practice. Tolmetin sodium inhibits both isoforms of cyclo-oxygenase enzyme. The inhibition of cyclo-oxygenase enzyme COX-I results in a number of undesirable effects such as gastrointestinal complaints. Moreover, tolmetin sodium has a short plasma half life (about 1-2 hours) that necessitates three-times a day administration of the drug (Jelvehgari et al., 2010). Therefore, tolmetin sodium is highly recommended to be prescribed in controlled release form. Furthermore, it would contribute to retain encapsulant during emulsification, decrease its loss during microspheres recovery (Giovanni $\boldsymbol{e t}$ al., 2002), and may provide a controlled release effect. Hence, the aim of this work was to formulate tolmetin sodium in controlled release oral dosage form. 
Emulsification/internal gelation has been suggested as an alternative to extrusion/external gelation in the encapsulation of several compounds including sensitive biologicals such as protein drugs (Chan et al., 2002). An emulsification/internal gelation method is proposed for producing small diameter alginate microspheres in large quantity. The difficulty in using dispersion/external gelation techniques with ionic polysaccharide is that the calcium source $\left(\mathrm{CaCl}_{2}\right)$ is insoluble in the oil phase. As an alternative, internal gelation of the dispersed alginate droplets may be initiated by releasing $\mathrm{Ca}^{2+}$ from an insoluble complex (calcium salt) through $\mathrm{pH}$ reduction (Friese et al., 2000; Gref et al., 2001).

Alginates, which are naturally occurring substances found in brown seaweed and algae have received much attention in pharmaceutical dosage forms, particularly as a vehicle for controlled drug delivery (Chen and Subirade, 2007). Alginates can be considered as block polymers, which mainly consist of mannuronic acid $(\mathrm{M})$, guluronic acid $(\mathrm{G})$ and mannuronic-guluronic (MG) blocks. One of the methods under consideration for the production of these drug delivery systems is emulsifica tion/internal gelation. In this context, the use of alginate microcapsules as oral delivery system for NSAIDs seems very attractive. The alginate matrix could protect the drug from hostile environments. Alginate possesses mucoadhesive properties which could increase the contact time between microcapsules and absorptive sites, and therefore could enhance the uptake of encapsulated drug. The low toxicity and low immunogenicity of alginate make this polymer a safe matrix (Silva et al., 2006).

Ethyl cellulose (EC ) is a derivative of cellulose in which some of the hydroxyl groups on the repeating anhydroglucose units are modified into ethyl ether groups, largely called as non-ionic ethyl ether of cellulose (Jelvehgari et al., 2010). EC has extensively been used for microencapsulation due to its many versatile properties such as biocompatible and compatible with many celluloses, resin and almost all plasticizers; non biodegradable, thus used in oral formulation only; stable against light, heat, oxygen and wetness and chemicals; non-toxic; non-irritant; Tablet binder to impart plastic flow properties to particles; ability to absorb pressure and hence protect the coating from fracture during compression (Bipul et al., 2010 and Sudhamani et al., 2010).

The prepared microspheres were evaluated for their morphology and surface structure, average particle size, production yield, drug loading efficiency, and drug release characteristics.

\section{EXPERIMENTAL PART}

\section{Materials}

Tolmetin sodium(TS) was kindly provided by Minapharm Co. for pharmaceuticals (10th Ramadan, Cairo, Egypt). Sodium alginate (NaA) and ethyl cellulose (EC): Sigma Chemical Co., St. Louis (USA). Calcium carbonate $\left(\mathrm{CaCO}_{3}\right)$, methylene chloride, glacial acetic acid, light liquid paraffin and potassium dihydrogen orthephosphate, Adwia, El-Nasr Pharm. Chem. Co. (Egypt). Other materials and solvents are of reagent or analytical grade, and they were used without further purification.

\section{Experimental Design:}

A Box-Behnken experimental design was employed to statistically optimize the formulation parameters of TS microsphere preparation for maximum entrapment, optimum diameter and controlled drug release. The Box-Behnken design was specifically selected since it requires fewer treatment combinations than other design in cases involving three or 
four factors. The Box- Behnken design is also ratable and contains statistical "missing corners" which may be useful when the experimenter is trying to avoid combined factor extremes. This property prevents a potential loss of data in those cases (Singh et al., 2010). A 2 factor 3 levels design was employed to design controlled release microspheres of tolmetin sodium. The two independent formulation variables analyzed during the study were drug to polymer ratio $\left(\mathrm{X}_{1}\right)$ and revolution per minute $\left(\mathrm{X}_{2}\right)$. The selected factors with the actual and coded levels as per the design are represented in Table (1). According to this design, 9 formulae of TS microspheres were prepared. Three levels of the speed were used 200, 400 and $600 \mathrm{rpm}$ denoted the values $-1,0$ and +1 in the above design, respectively. Drug: polymer ratio was varied to be (1:2), (1:3) and (1:4), also denoted the values $-1,0$ and +1 , respectively. The dependent variables to be tested for the prepared TS microspheres were chosen to be the loading efficiency $\left(\mathrm{Y}_{1}\right)$, Release at the end of $2 \mathrm{~h}\left(\mathrm{Y}_{2}\right)$ and release at the end of $8 \mathrm{~h}\left(\mathrm{Y}_{3}\right)$.

Table(1): Composition of different suggested formulae of tolmetin sodium microspheres using sodium alginate-ethyl cellulose copolymers according to pharmaceutical point of view.

\begin{tabular}{|c|c|c|c|c|c|c|}
\hline Form. No. & Drug (gm) & Sod. Alg. (gm) & $\begin{array}{l}\text { EC } \\
(\mathrm{gm})\end{array}$ & $\begin{array}{l}\text { Ca. carbonate } \\
(\mathrm{gm})\end{array}$ & $\begin{array}{l}\text { Speed } \\
(\text { rpm) }\end{array}$ & $\begin{array}{l}\text { Tot. weight } \\
\text { (gm) }\end{array}$ \\
\hline F1 & 0.5 & 0.5 & 1 & 0.375 & 200 & 1.875 \\
\hline F2 & 0.5 & 0.5 & 0.5 & 0.375 & 600 & 2.375 \\
\hline F3 & 0.5 & 0.5 & 1.5 & 0.375 & 600 & 2.875 \\
\hline F4 & 0.5 & 0.5 & 0.5 & 0.375 & 200 & 1.875 \\
\hline F5 & 0.5 & 0.5 & 1 & 0.375 & 400 & 2.375 \\
\hline F6 & 0.5 & 0.5 & 0.5 & 0.375 & 400 & 1.875 \\
\hline F7 & 0.5 & 0.5 & 1.5 & 0.375 & 400 & 2.875 \\
\hline F8 & 0.5 & 0.5 & 1.5 & 0.375 & 200 & 2.875 \\
\hline F9 & 0.5 & 0.5 & 1 & 0.375 & 600 & 2.375 \\
\hline
\end{tabular}

\begin{tabular}{|c|c|c|c|}
\hline Speed & $+1=600$ & $0=400$ & $-1=200$ \\
\hline Drug: polymer ratio & $+1=1: 4$ & $0=1: 3$ & $-1=1: 2$ \\
\hline
\end{tabular}

\section{Preparation of Alginate Coated Microcapsules}

Composition of different suggested formulae of tolmetin sodium microspheres is listed in table (1). A basal encapsulation protocol was used to prepare microspheres (Silva $\boldsymbol{e t}$ al., 2006). In brief, sodium alginate solution were prepared by dissolving the specified amount of the polymer (0.5) in $30 \mathrm{ml}$ hot water and then tolmetin sodium was dispersed in this solution using a magnetic stirrer for 10 minutes. A suspension of $\mathrm{CaCO}_{3}$ at $5 \%(\mathrm{w} / \mathrm{v})$ was added to the alginate-tolmetin sodium solution, after homogenization, the mixture was dispersed into paraffin oil (30\% internal phase ratio, v/v) containing $1 \%$ span 80 as emulsifying agent and was emulsified by stirring at different speeds. After emulsification for $15 \mathrm{~min} ., 20 \mathrm{ml}$ of paraffin oil containing $0.2 \mathrm{ml}$ glacial acetic acid (acid/Ca molar ratio of 3.5) were added to the w/o emulsion. Stirring was continued for 20 minutes to permit calcium carbonate solubilization and formation of calcium alginate microsphere then $100 \mathrm{ml}$ of ethyl cellulose solution of specific concentrations $(5 \%, 10 \%, 15 \% \mathrm{w} / \mathrm{v}$ in acetone) was added. The concentrations of tolmetin sodium to sodium alginate-ethyl cellulose copolymers were prepared in different drug: polymer ratios 1:2, 1:3 and 1:4. The stirring was continued for 45 minutes after this step. Then, $50 \mathrm{ml}$ of petroleum ether was added to rigidize the ethyl cellulose coat. After 10 minutes, the microspheres were filtered and washed by applying cold 
petroleum ether (three times $\times 50 \mathrm{ml}$ ) to remove all adhered liquid paraffin. Microspheres were dried for 48 hours at room temperature and stored in a dessicator until starting experiment.

\section{Production yield determination}

The yield of the microspheres was determined in triplicate by dividing the weight of the prepared microspheres by the original amount of the polymer and drug used and the results were expressed as a percentage according to the equation (Jelvehgari et al., 2010).

$\%$ Yield $=($ Actual weight of product $/$ Total weight of excipient and drug $) \times 100$

\section{Particle size determination}

The dried microspheres were weighed and sized using USP standard sieve (Rx-86-1, Cole-Palmer Instrument Co., USA). The fraction of microspheres remaining on each sieve was collected and the mean particle size of the microspheres was assigned as the percentage of microspheres retained at each sieve multiplied by the average particle size of the sieve used (Choi et al., 2002). Each experiment was carried out in triplicate.

\section{Determination of drug content}

The drug content of the prepared tolmetin sodium microspheres was determined by the digestion method (Perumal, 2001) and the experiments were carried out in triplicate. One hundred micrograms of tolmetin sodium microparticles was crushed carefully in a glass mortar and a definite weight was transferred to a $100 \mathrm{ml}$ volumetric flask using phosphate buffer $\mathrm{pH}$ 7.4. The volumetric flask was completed to the volume with phosphate buffer $\mathrm{pH}$ 7.4 then agitated for $5 \mathrm{~min}$ each hour for $5 \mathrm{~h}$. The sample was filtered and the drug concentration was determined spectrophotometerically at $324 \mathrm{~nm}$ (Spectrophotometer UV. 1601, Shimadzu Co., Japan). The same procedure was applied for the plain formula, which was used as a blank.

\section{Microspheres morphology}

The morphology of the microsphere surfaces was investigated using scanning electron microscopy. Microspheres were spread on a carbon double-adhesive layer on a metal holder and gold-coated using Ion-Sputtering device (Jeol Fine-Coat JFC 1100E, Jeol Ltd., Tokyo, Japan). The microparticles were scanned by Scanning Electron Microscope (SEM) (Jeol JSM-5400 LV, Jeol Ltd., Tokyo, Japan).

\section{In vitro release of tolmetin sodium microspheres}

Dissolution testing of the prepared microspheres equivalent to $100 \mathrm{mg}$ of tolmetin sodium was performed with the rotating basket apparatus according to USP 24 apparatus 1 (SR11 6 Flask, Hanson Co., USA). Hard gelatin capsules No. 2 filled with known amount of microspheres were used for dissolution testing using basket speed of $50 \mathrm{rpm}$ and a temperature of $37{ }^{\circ} \mathrm{C} \pm 0.5$. Regarding the dissolution medium, fifty $\mathrm{ml}$ of phosphate buffer pH 7.4 was used as the release medium for eight hours (Mahrous et al., 2010). Three milliliters of each sample were removed at specific intervals throughout the whole $8 \mathrm{~h}(0.25$, $0.5,1,1.5,2,2.25,2.5,3,4,5,6,7$ and $8 \mathrm{~h}$ ). The samples were diluted appropriately with the release medium and absorbance was measured at the predetermined $\lambda$ max of each medium against a blank of this medium. The withdrawn samples were replaced with equal volumes of the release medium. It is worthy to mention that the experiments were carried out in triplicate.

\section{Regression analysis:}

The targeted response parameters were statistically analyzed by applying one-way ANOVA at 0.05 level in Stategraphic plus soft ware (Statpoint Tech., Inc. Warrenton, Virginia). The individual parameters were evaluated using the $\mathrm{F}$ test and quadratic models of the form $Y=\beta_{0}+\beta_{1} X_{1}+\beta_{2} X_{2}+\beta_{3} X_{1} X_{2}+\beta_{4} X_{1}^{2}+\beta_{5} X_{2}^{2}$ were generated for each response parameter using multiple linear regression analysis (MLRA), where $Y$ is the level 
of the measured response; $\beta_{0}$ is the intercept $\beta_{1}$ to $\beta_{5}$ are the regression coefficients. $X_{1}$ and $\mathrm{X}_{2}$ stand for the main effects; $\mathrm{X}_{1} \mathrm{X}_{2}$ is the interaction between the main effects; $\mathrm{X}_{1}^{2}$ and $\mathrm{X}_{2}^{2}$ are the quadratic terms of the independent variables that were used to simulate the curvature of the designed sample space. A backward elimination procedure was adopted to fit the data into different predictor equations. The quadratic models generated by regression analysis were used to construct the 3-dimensional graphs in which response parameter $\mathrm{Y}$ was represented by a curvature surface as a function of $X$. The effect of the independent variables on each response parameters was visualized from the contour plots.

Numerical optimization using desirability approach was employed to locate the optimal settings of the formulation variables to obtain the desired response. An optimized formulation was developed by setting constraints on the dependent and independent variables. The new formulation was evaluated for the responses and the experimental values obtained were compared with those predicted by the mathematical models.

\section{Kinetics of the in vitro release of tolmetin sodium capsules}

The kinetic parameters for the in vitro release of tolmetin sodium were determined and then analyzed in order to find the proper order of the drug release. Zero and first order kinetics, as well as controlled diffusion or Higuchi diffusion model (Higuchi et al., 1963).

\section{RESULTS AND DISCUSSION}

\section{(1) Microcapsule Morphology}

The microspheres prepared with alginate/ethyl cellulose copolymers were examined using the light microscope, Figure (1). It can be seen that at drug to polymer ratio 1:2 there is a hollow cavity for the microspheres by internal gelation $(1(a))$, Figure $1(b)$ is the enlarged view of the outer surface, which reveals the clear loose network structure with the larger pores (dark area). Figure $1(d)$ reveals that at drug to polymer ratio 1:4 the prepared microspheres are spherical in shape with more smooth surface, more intact surface with smaller pores.

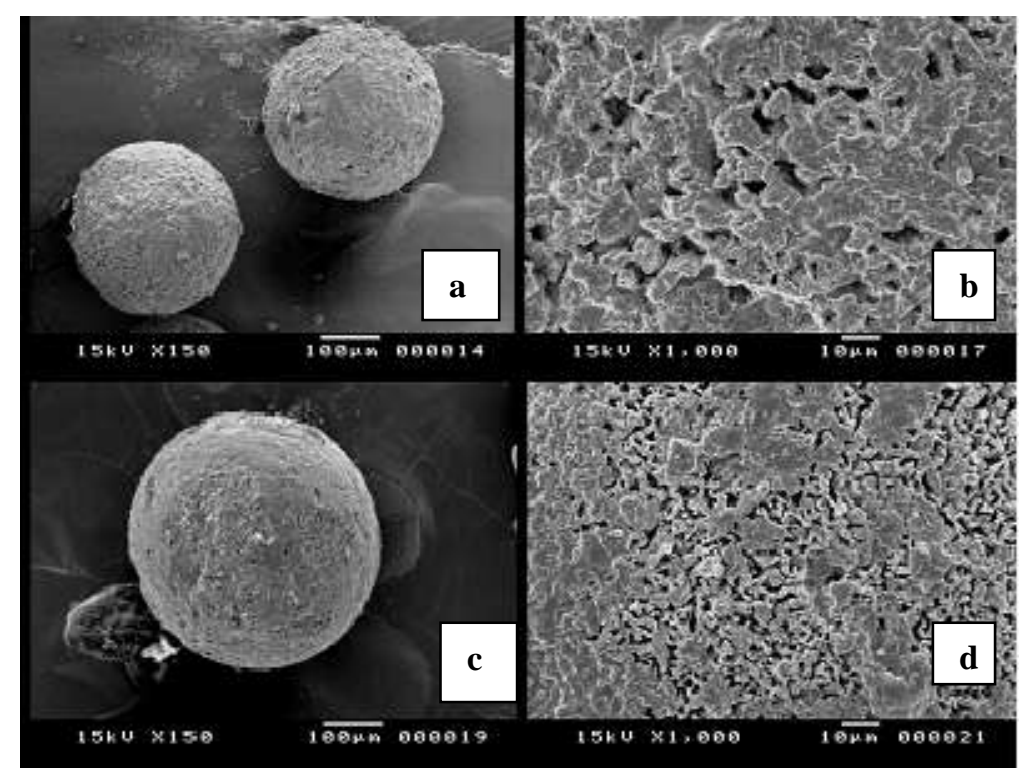

Figure (1): SEM photographs of tolmetin sodium microspheres prepared by internal gelation (a) full view at 1:2 drug to polymer ratio, $(b)$ outer surface at 1:2 drug to polymer ratio, $(c)$ full view at 1:4 drug to polymer ratio, $(d)$ outer surface at 1:4 drug to polymer ratio. 
A similar effect on the microcapsule shape was stated for salbutamol sulfate microspheres at different ethyl cellulose concentrations. Those particles were spherical in shape and exhibited porous surfaces. The surface of the drug loaded microspheres manifested the presence of drug particles as compared to blank microspheres. Surface study of the microspheres after release study showed bigger pores suggesting that the drug is released though pores and the mechanism of drug release was diffusion controlled (Bipul $\boldsymbol{e t}$ al., 2010).

Another study for ibuprofen ethyl cellulose revealed that the microspheres had good spherical geometry as evidenced by the SEM photographs. The surface of the microspheres was quite smooth ( Sudhamani et al., 2010).

\section{The particle size of the microspheres}

The particle size analysis of alginate-ethyl cellulose coated microspheres was done using sieve analysis procedure. The mean particle size values $( \pm$ SD) for formulations number 1 to 9 , were $433 \pm(35.1), 341 \pm(41.5), 441 \pm(39.7), 376 \pm(39.8), 425 \pm(42.6)$, $355 \pm(32.9), 467 \pm(45.2), 482 \pm(47.9), 405 \pm(43.1) \mu \mathrm{m}$ respectively. Drug to polymer ratio markedly affected the microcapsule size at the three different ethyl cellulose concentrations. The mean particle size of the prepared microspheres increased with increasing the amount of the copolymers. No clear relationship was found between the particle size of the microspheres and the change in polymer concentrations. Stirring speed is the most important parameter for controlling the drug/matrix dispersion's droplet size in the continuous phase. It was shown that increasing the stirring speed generally results in decreased microparticle size, as it produces smaller emulsion droplets through stronger shear forces and increased turbulence. The same results were obtained in microencapsulation of ibuprofen with eudragit RS100 ( Perumal, 2001).

\section{Microcapsule production yield}

The percentage production yield for the nine prepared formulations was $94.37 \pm 3.11$, $87.62 \pm 4.23,85.14 \pm 4.02,88.06 \pm 5.08,95.36 \pm 4.32,92.8 \pm 3.98,83.82 \pm 4.51,78.40 \pm 4.11$ and $88.33 \pm 5.44 \%$, respectively, see Table (2). There was no obvious difference between the yield of different formulations on varying both the drug to polymer ratio and the speed.

Table(2): $\quad$ Production yield and drug loading efficiency of tolmetin sodium microspheres prepared using sodium alginate-EC as coating polymers.

\begin{tabular}{|c|c|c|c|c|}
\hline $\begin{array}{c}\text { Formulation } \\
\text { number }\end{array}$ & $\begin{array}{c}\text { Yield } \\
(\%)\end{array}$ & $\begin{array}{c}\text { Theoretical drug } \\
\text { content } \\
(\%)\end{array}$ & $\begin{array}{c}\text { Actual drug } \\
\text { content } \\
(\%)\end{array}$ & $\begin{array}{c}\text { Loading } \\
\text { efficiency }(\%) \\
\text { Mean } \pm \text { SD }\end{array}$ \\
\hline 1 & $94.37 \pm 3.11$ & 25.00 & $22.10 \pm 1.51$ & $88.4 \pm 4.56$ \\
\hline 2 & $87.62 \pm 4.23$ & 33.33 & $26.23 \pm 2.59$ & $78.7 \pm 5.19$ \\
\hline 3 & $85.14 \pm 4.02$ & 20.00 & $15.12 \pm 1.08$ & $75.6 \pm 4.32$ \\
\hline 4 & $88.06 \pm 5.08$ & 33.33 & $30.23 \pm 1.99$ & $90.7 \pm 3.98$ \\
\hline 5 & $95.36 \pm 4.32$ & 25.00 & $20.37 \pm 1.85$ & $81.5 \pm 5.57$ \\
\hline 6 & $92.80 \pm 3.98$ & 33.33 & $26.39 \pm 2.04$ & $79.2 \pm 4.09$ \\
\hline 7 & $83.82 \pm 4.51$ & 20.00 & $15.62 \pm 0.94$ & $78.1 \pm 3.79$ \\
\hline 8 & $78.40 \pm 4.11$ & 20.00 & $18.46 \pm 1.26$ & $92.3 \pm 5.04$ \\
\hline 9 & $88.33 \pm 5.44$ & 25.00 & $18.70 \pm 1.66$ & $74.8 \pm 4.99$ \\
\hline
\end{tabular}




\section{Differential scanning calorimetry (DSC)}

The drug may have been dispersed in crystalline or amorphous form or dissolved in the polymeric matrix during the formation of microspheres. Any abrupt or drastic change in the thermal behavior of either the drug or polymer may indicate a possible drug-polymer interaction. The endothermic peak of pure drug was observed at about $159.31^{\circ} \mathrm{C}$ (Figure 2). However, in the thermogram of the microparticles, (containing Na-alg and EC) there was an endothermic peak of the drug melting with a lower intensity than the pure drug peak, suggesting the crystalline state of the drug in the microspheres. The DSC showed the stable character of tolmetin sodium in the drug loaded microspheres and revealed crystalinity form. Similar results were observed with mefenamic acid microspheres prepared by modified emulsion solvent evaporation technique (Jelvehgari et al., 2011).

\section{Curve A}

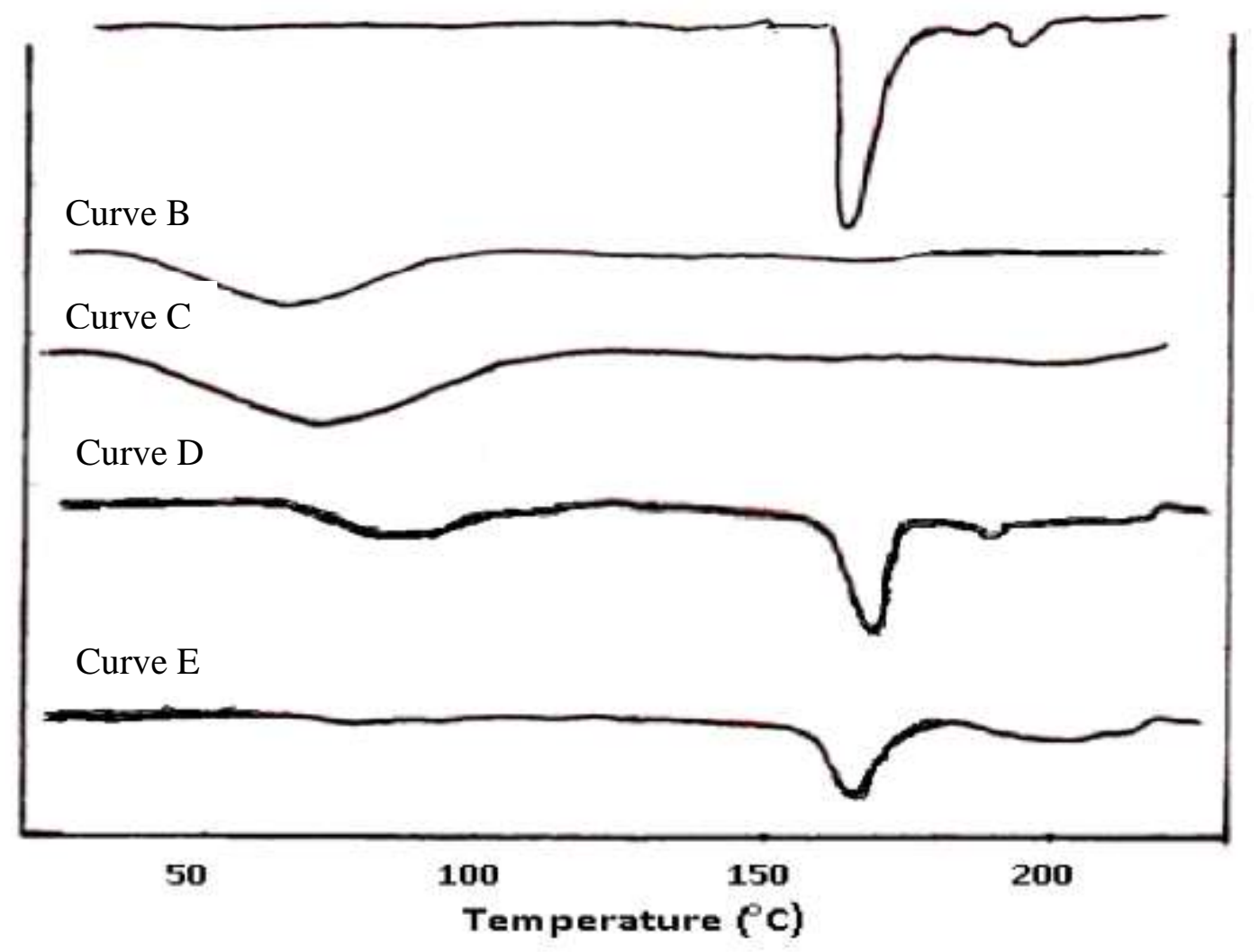

Figure (2): Differential Scanning Calorimetry of tolmetin sodium (curve A),Ethyl cellulose (curve B),sodium alginate (curve C),physical mixture (Curve D) and the prepared microspheres (curve E).

\section{Loading Efficiency}

The data obtained in case of sodium alginate- ethyl cellulose microspheres are listed in Table (2). The actual drug content values for formulations number 1 to 9 were $22.10 \pm 1.51,26.23 \pm 2.59,15.12 \pm 1.08,30.23 \pm 1.99,20.37 \pm 1.85,26.39 \pm 2.04,15.62 \pm 0.94$, $18.46 \pm 1.26$ and $18.70 \pm 1.86 \%$, respectively. According to drug to polymer ratio, the calculated theoretical drug content value for formulations number 2, 4 and 6 was $33.33 \%$ ,while for formulations number 1,5 and 9 was $25 \%$ and for formulations number 3,7 and 8 was $20 \%$. Thus, the loading efficiency values $( \pm$ SD) for the nine formulations were 
computed as $88.4 \pm(4.56), 78.7 \pm(5.19), 75.6 \pm$ (4.32), 90.7 \pm (3.98), $81.5 \pm(5.57), 79.2 \pm$

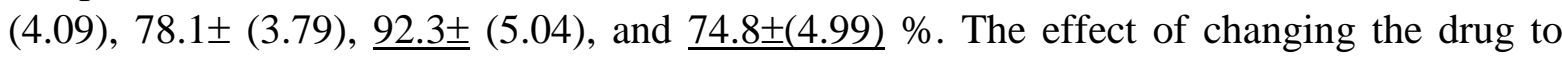
polymer ratio on the drug loading efficiency was investigated, at each ethyl cellulose concentration, using ANOVA test. The drugs loading efficiency values depended on the speed of rotation and were found to range from $74.8 \pm 3.67$ to $92.3 \pm 1.88$. The output shows the results of fitting a multiple linear regression model to describe the relationship between Drug Polymer Ratio and drug loading efficiency. The equation of the fitted model is $\left(\mathrm{Y}_{1}=\right.$ $0.461394-0.00564972 \mathrm{X}_{1)}$. Since the P-value in the ANOVA table is greater or equal to 0.10 , there is not a statistically significant relationship between the variables at the $90 \%$ or higher confidence level. The R-Squared statistic indicates that the model as fitted explains $0.188324 \%$ of the variability in drug polymer ratio. On the other hand, the output shows the results of fitting a multiple linear regression model to describe the relationship between Speed and drug loading efficiency. The equation of the fitted model is $\left(\mathrm{Y}_{1}=9.91996\right.$ $0.121469 \mathrm{X}_{1}$ ). Since the P-value in the ANOVA table is less than 0.01 , there is a statistically significant relationship between the variables at the $99 \%$ confidence level. The R-Squared statistic indicates that the model as fitted explains $87.0527 \%$ of the variability in Speed. The model indicated that the speed emerged as the lone factor, which exerted a significant influence on the drug loading efficiency.

The 3-D plot, Figure (3) showed that the drug loading efficiency increased from $78.17 \pm 1.12$ to $90.7 \pm 0.62$ and from $75.6 \pm 1.61$ to $92.3 \pm 1.15$ at higher and lower levels of speed with constant drug to polymer ratio. The improvement in percent drug loading efficiency with decreased speed levels was due to the fact that more drugs gets dissolved and incorporated in the polymer matrix with low speed of rotation. A linear relationship between the two variables investigated on the percent drug incorporation was clearly seen from the corresponding contour plots which suggested that percent drug loading efficiency can be enhanced using low speed of rotation (Figure 4). Microencapsulation by the emulsification/internal gelation method involves two major steps, the formation of stable droplets of the polymer solution with drug incorporated in as an emulsified system and the subsequent solidification of the droplets. These two steps have a significant effect on size and encapsulation efficiency of microspheres. Similar results were obtained in preparation of biodegradable paclitaxel loaded alginate microparticles for pulmonary delivery (Alipour $\boldsymbol{e t}$ al., 2010)

Table(3): Factor combinations and response parameters of tolmetin sodium microspheres prepared as $3^{2}$ factorial design.

\begin{tabular}{|c|c|c|c|c|c|}
\hline - & $X_{1}$ & $\mathbf{X}_{2}$ & $\% \operatorname{LE}(\% \mathrm{w} / \mathrm{w})^{\mathrm{a}}$ & $\mathrm{Rel}_{2}{ }^{\mathrm{a}}$ & $\operatorname{Rel}_{8}{ }^{a}$ \\
\hline 1 & $0(1: 3)$ & $-1(200)$ & $88.3 \pm 2.11$ & $23.20 \pm 0.98$ & $69.41 \pm 2.02$ \\
\hline 2 & $-1(1: 2)$ & $1(600)$ & $78.2 \pm 2.56$ & $36.69 \pm 1.32$ & $93.31 \pm 3.32$ \\
\hline 3 & $1(1: 4)$ & $1(600)$ & $75.3 \pm 2.63$ & $29.27 \pm 1.12$ & $75.03 \pm 2.67$ \\
\hline 4 & $-1(1: 2)$ & $-1(200)$ & $90.8 \pm 3.54$ & $28.33 \pm 1.21$ & $79.27 \pm 1.76$ \\
\hline 5 & $0(1: 3)$ & $0(400)$ & $81.7 \pm 1.98$ & $27.52 \pm 1.57$ & $78.98 \pm 3.51$ \\
\hline 6 & $-1(1: 2)$ & $0(400)$ & $79.0 \pm 3.65$ & $31.09 \pm 1.11$ & $85.15 \pm 3.08$ \\
\hline 7 & $1(1: 4)$ & $0(400)$ & $78.1 \pm 3.56$ & $25.31 \pm 1.89$ & $69.27 \pm 2.67$ \\
\hline 8 & $1(1: 4)$ & $-1(200)$ & $92.3 \pm 1.88$ & $20.07 \pm 1.14$ & $65.06 \pm 2.03$ \\
\hline 9 & $0(1: 3)$ & $1(600)$ & $74.8 \pm 3.67$ & $32.21 \pm 1.09$ & $83.89 \pm 2.21$ \\
\hline
\end{tabular}

The parentheses in the data represent the decoded factor levels. $\mathrm{X}_{1}$ represents drug to polymer ratio; $\mathrm{X}_{2}$ represents speed. \% LE $=$ Percentage loading efficiency; $\operatorname{Rel}_{2}=$ Release at the end of $2 \mathrm{~h} ; \mathrm{Rel}_{8}=$ Release at the end of $8 \mathrm{~h}$.

${ }^{a}$ The values represent the average of three determinations $(n=3)$ 


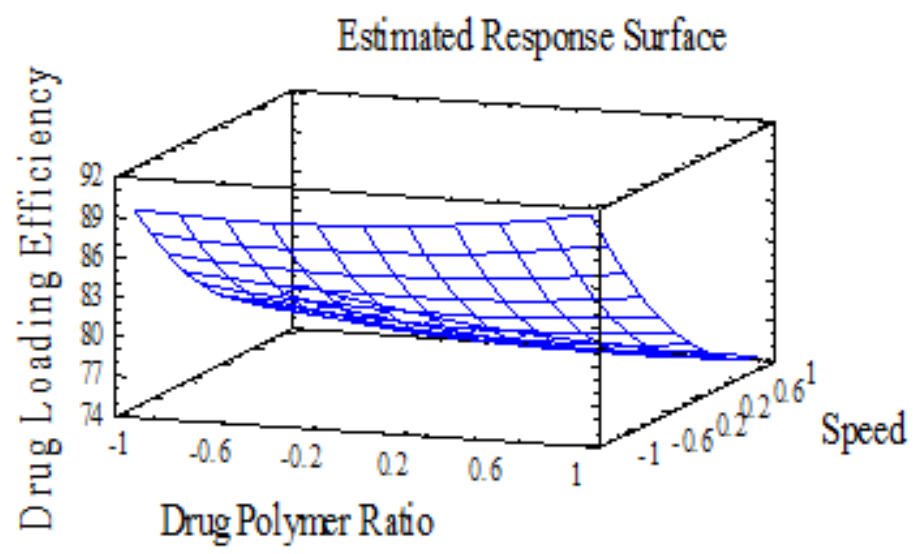

Figure (3) ; Three dimensional contour plot for the effect of drug-polymer ratio $\left(\mathrm{X}_{1}\right)$ and speed $\left(\mathrm{X}_{2}\right)$ on the drug loading efficiency $\left(\mathrm{Y}_{1}\right)$.

Contours of Estimated Response Surface

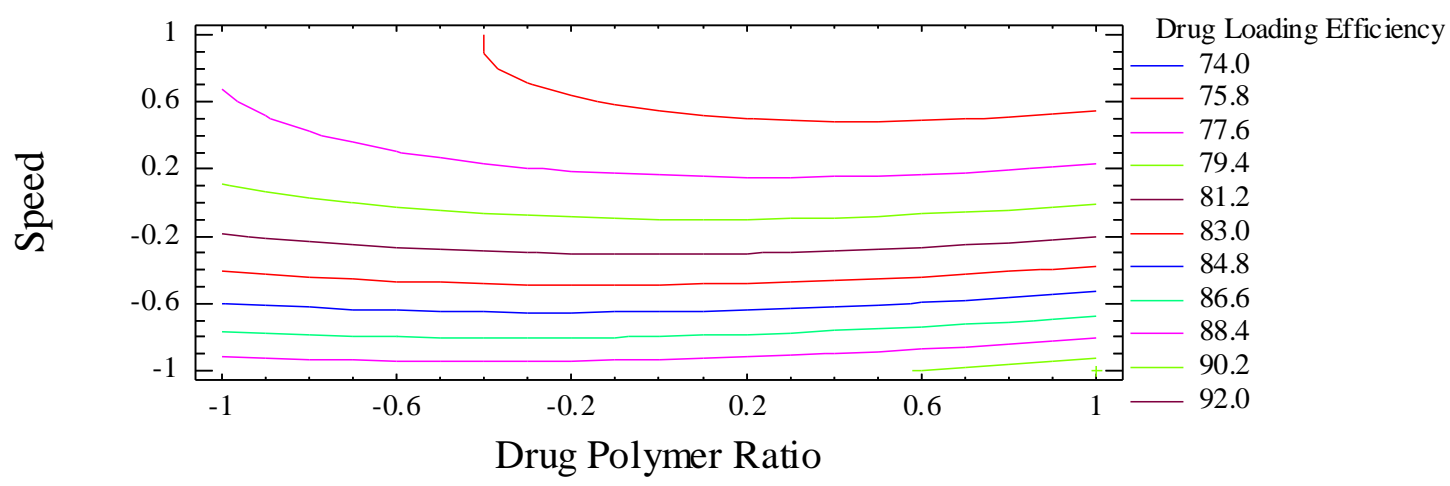

Figure (4) : Two dimensional contour plot for the effect of drug-polymer ratio $\left(\mathrm{X}_{1}\right)$ and speed $\left(\mathrm{X}_{2}\right)$ on the drug loading efficiency $\left(\mathrm{Y}_{1}\right)$.

\section{In vitro release of tolmetin sodium microspheres}

Figure (5) shows the in-vitro release of tolmetin sodium from its capsules containing formulae ( F2, F6 and F4) using constant drug: polymer ratio 1:2 $\left(\mathrm{X}_{1}\right)$ with variable speed of rotations, $600 \mathrm{rpm}$ for F2; 400 for $\mathrm{F} 6$ and $200 \mathrm{rpm}$ for F4; $\left(\mathrm{X}_{2}\right)$. The maximum and minimum percent released were observed to be $36.46 \%$ and $28.43 \%$ at the end of two hours $\left(\mathrm{Y}_{2}\right)$. The maximum and the minimum in-vitro release after eight hours $\left(\mathrm{Y}_{3}\right)$ of dissolution were found to be equal $93.31 \pm 3.32 \%$ and $79.27 \pm 1.76 \%$, respectively. The investigated formulae containing tolmetin sodium capsules (F2, F4 and F6) can be arranged, in descending order, concerning the in vitro release within eight hours as follows: F2 > F6 > F4 respectively.

Figure (6) show the in-vitro release of tolmetin sodium from its capsules containing formulae $\mathrm{F} 1, \mathrm{~F} 5$ and $\mathrm{F} 9$ using drug to polymer ratio 1:3 $\left(\mathrm{X}_{1}\right)$ with variable speeds, $200 \mathrm{rpm}$ for $\mathrm{F} 1$; $400 \mathrm{rpm}$ for $\mathrm{F} 5$, and $600 \mathrm{rpm}$ for $\mathrm{F} 9\left(\mathrm{X}_{2}\right)$. The maximum and minimum percent released were observed to be $32 \pm 1.09 \%$ and $23 \pm 0.98 \%$ at the end of two hours $\left(\mathrm{Y}_{2}\right)$. The maximum and minimum in-vitro release after eight hours of dissolution $\left(\mathrm{Y}_{3}\right)$ was found to be $83.89 \pm 2.21 \%$ and $69.41 \pm 2.02 \%$. The investigated formulae containing tolmetin sodium 
capsules (F1, F5 and F9) can be arranged, in descending order, concerning the in-vitro release within 4 hours dissolution as follows: F9 > F5> F1 respectively.

Figure (7) show the in-vitro release of tolmetin sodium from its capsules containing formulae F3,F7 and F8 using constant drug-polymer ratio 1:4 $\left(\mathrm{X}_{1}\right)$ with variable speeds, 200 $\mathrm{rpm}$ for F8; $400 \mathrm{rpm}$ for F7 and $600 \mathrm{rpm}$ for F3 $\left(\mathrm{X}_{1}\right)$. The maximum and minimum percent released were observed to be $29.27 \pm 1.12$ and $20.07 \pm 1.14$ after the end of two hours $\left(\mathrm{Y}_{2}\right)$. The maximum and minimum in-vitro releases after eight hours $\left(\mathrm{Y}_{3}\right)$ of dissolution were found to be $75.03 \pm 2.67$ and $65.06 \pm 2.03 \%$. The investigated formulae containing tolmetin sodium capsules (F3,F7 and F8) can be arranged, in descending order, concerning the invitro release within 4 hours dissolution, as follows: F3 $>$ F7 $>$ F8, respectively.

The best formulae for the in-vitro release after whole dissolution period ( 8 hours) were observed to be F8, F7, F1, F3, F5, F4, F9, F6 and F2. The equation of the fitted model which study the effect of Drug Polymer Ratio and speed on drug release after 2 hours is (Release $2 \mathrm{hrs}=27.8889-3.5 \mathrm{X}_{1}+4.33333 \mathrm{X}_{2}$ ). Since the P-value in the ANOVA table is less than 0.01 , there is a statistically significant relationship between the variables at the $99 \%$ confidence level. The R-Squared statistic indicates that the model as fitted explains $98.5588 \%$ of the variability in release 2 hours. The drug polymer ratios were found to have a negative influence on the drug release whereas the speed had a positive influence on the drug release. The response surface plots (Figure 8) illustrate that the drug release at the end of two hours decreased from $28.33 \pm 1.54 \%$ to $20.07 \pm 1.23 \%$ and from $36.69 \pm 1.89$ to $29.27 \pm 1.42 \%$ at low and high levels of drug to polymer ratio, respectively as the polymer content increased. This can be due to better incorporation of the drug in the polymeric matrices, which left behind fewer drug crystals on the surface with increase in the polymer content.

The levels of speed were found to have a positive influence on the drug release after two hours. It was evident from the 3-D plots (Figure 8) that the drug release at the end of two hours increased from $28.33 \pm 1.21 \%$ to $36.69 \pm 1.32 \%$ and from $20.07 \pm 1.14 \%$ to $29.27 \pm 1.12 \%$ at low and high speed levels respectively. This increase in drug release was due to the decrease in particle size of microspheres which increased surface area and this lead to increased permeability of ethyl cellulose. A linear relationship between the two independent variables on drug release after two hours was clear from the corresponding contour plots(Figure 9), which also indicated that drug release could be minimized using low levels of speed at high polymer levels

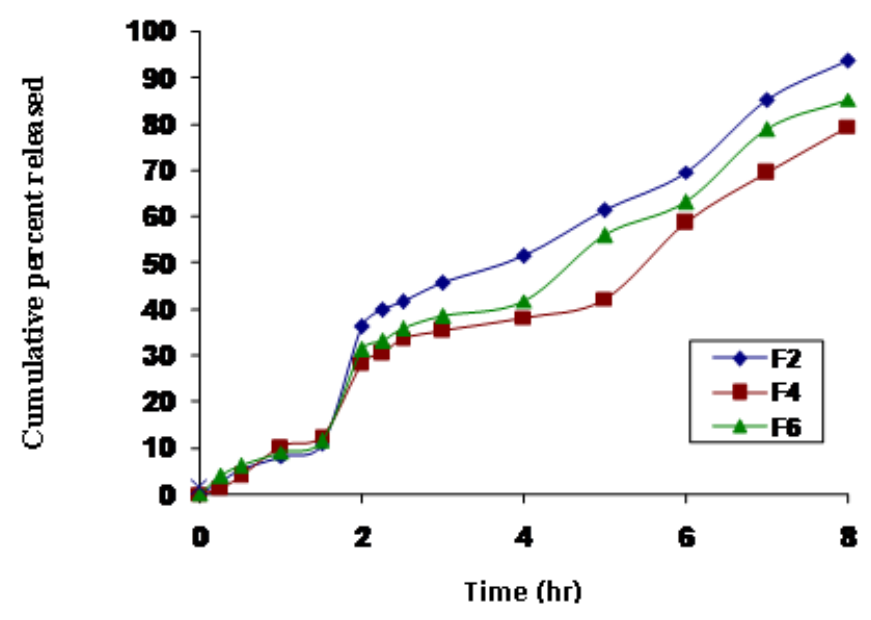

Figure (5): Release profiles of tolmetin sodium microspheres prepared at drug to polymer ratio of $1: 2$. 


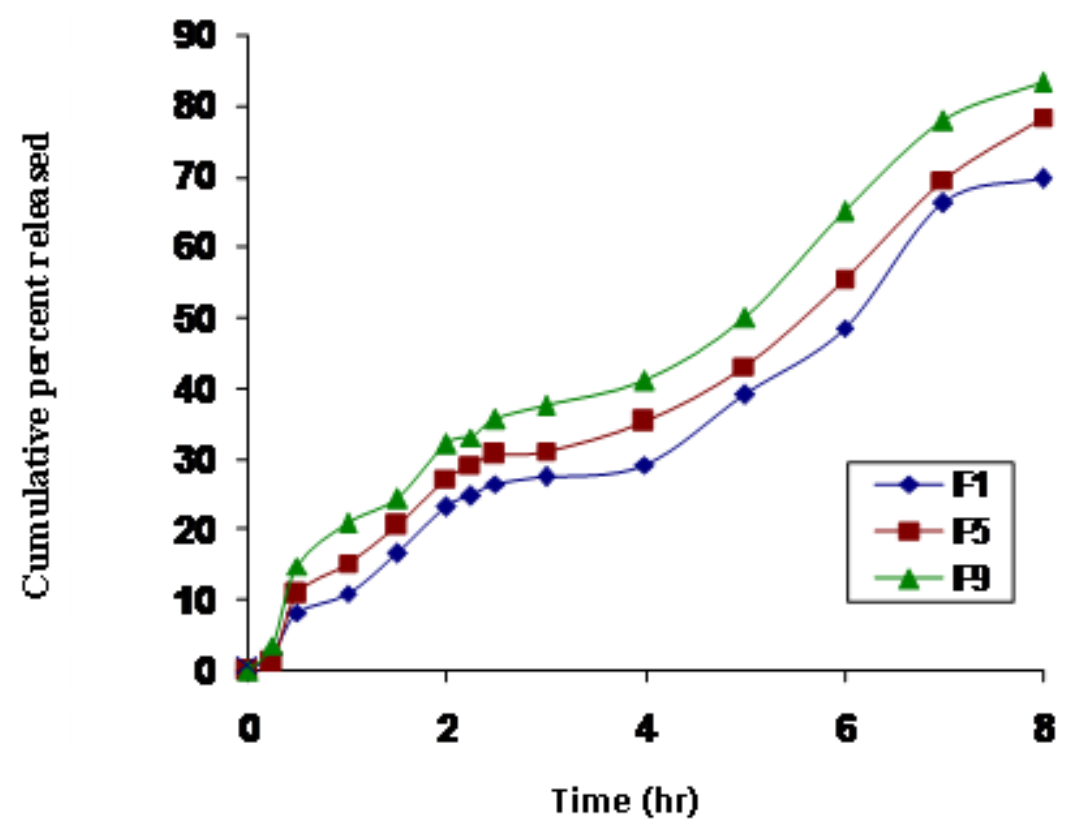

Figure (6): Release profiles of tolmetin sodium microspheres prepared at drug to polymer ratio of 1:3.

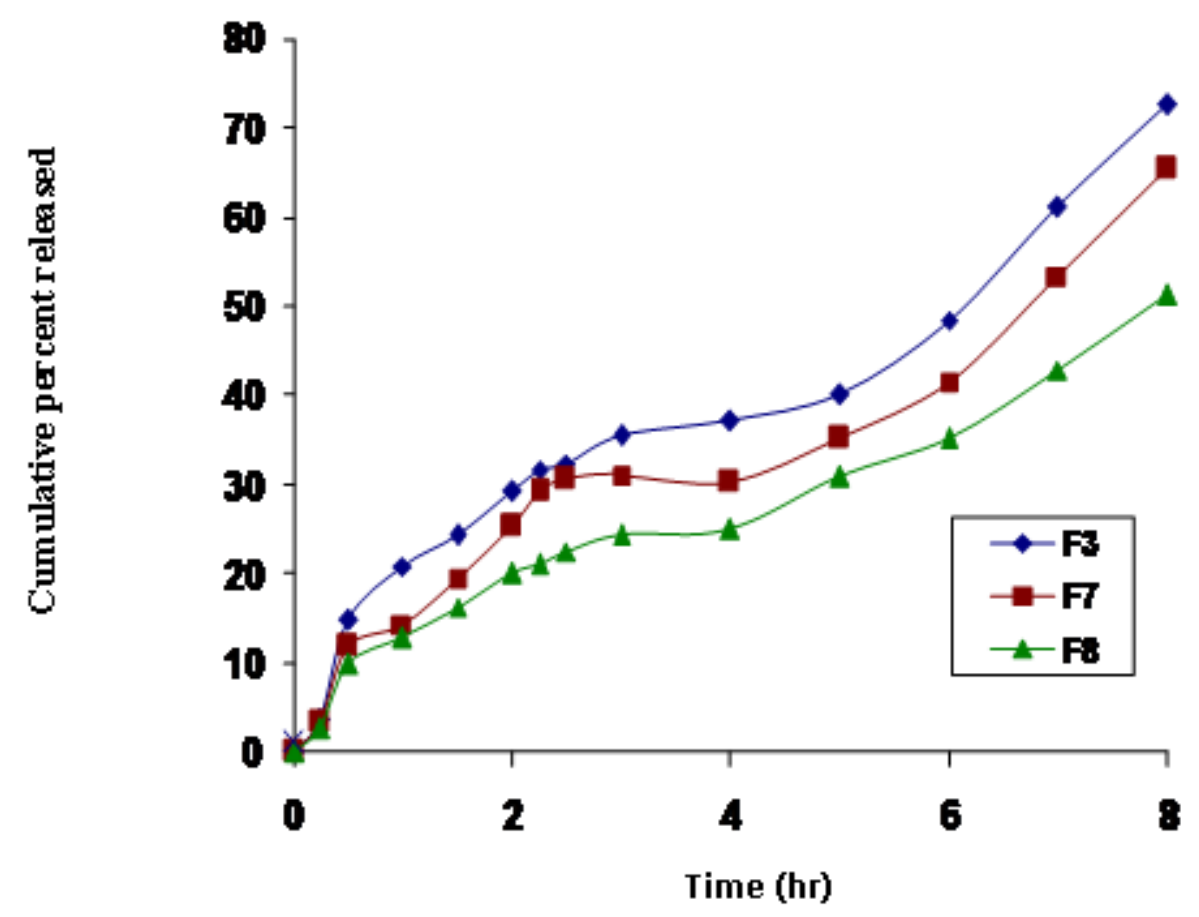

Figure (7): Release profiles of tolmetin sodium microspheres prepared at drug to polymer ratio of 1:4.

The equation of the fitted model which study the effect of Drug Polymer Ratio and speed on drug release after 8 hours is (Release $8 \mathrm{hrs}=77.3333-8.0 \mathrm{X}_{1}+6.33333 \mathrm{X}_{2}$ ). Drug polymer ratio and speed had a significant effect on drug release at the end of 8 hours with $\mathrm{F}$ value of 165.35 ( $p<0.0001)$. The R-Squared statistic indicates that the model as fitted explains $98.218 \%$ of the variability in Rel 8 hours. The drug polymer ratios were found to have a negative influence on the drug release whereas the speed had a positive influence on the drug release. The response surface plots (Figure 10) illustrate that the drug release at the 
end of eight hours decreased from $79.27 \pm 1.76 \%$ to $65.06 \pm 2.03 \%$ and from $93.31 \pm 3.32$ to $75.03 \pm 2.67 \%$ at low and high levels of drug to polymer ratio, respectively as the polymer content increased. This can be due to better incorporation of the drug in the polymeric matrices, which left behind fewer drug crystals on the surface with increase in the polymer content.

The levels of speed were found to have a positive influence on the drug release after eight hours. It was evident from the 3-D plots that the drug release at the end of eight hours increased from $79.27 \pm 1.76 \%$ to $93.31 \pm 3.32 \%$ and from $65.06 \pm 2.03 \%$ to $75.03 \pm 2.67 \%$ at low and high speed levels respectively. This increase in drug release was due to the decrease in particle size of microspheres which increased surface area and this lead to increased permeability of ethyl cellulose. A linear relationship between the two independent variables on drug release after eight hours was clear from the corresponding contour plots (Figure 11), which also indicated that drug release could be minimized using low levels of speed at high polymer levels

\section{Estimated Response Surface}

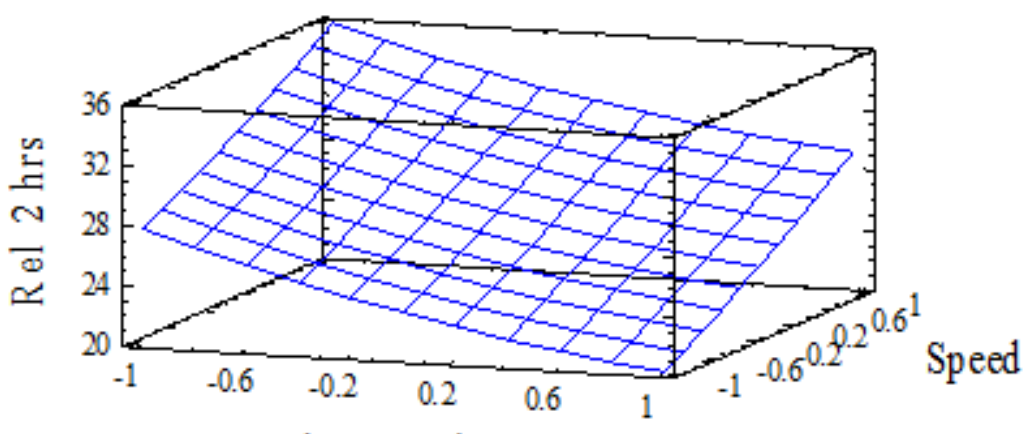

Drug Polymer Ratio

Figure (8) : Three dimensional contour plot for the effect of drug-polymer ratio $\left(\mathrm{X}_{1}\right)$ and speed $\left(\mathrm{X}_{2}\right)$ on drug release after two hours $\left(\mathrm{Y}_{2}\right)$.

Contours of Estimated Response Surface

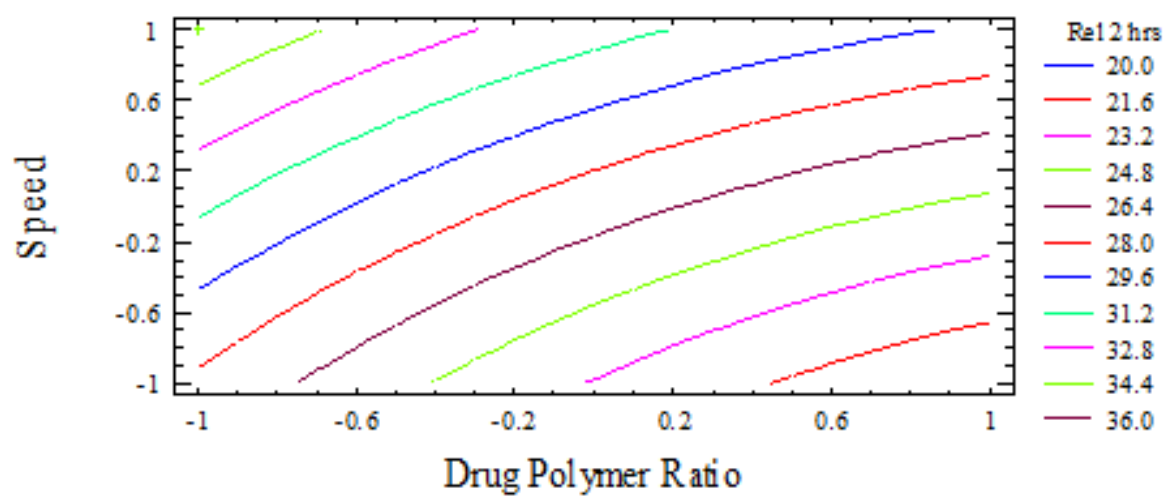

Figure (9) : Two dimensional contour plot for the effect of drug-polymer ratio $\left(\mathrm{X}_{1}\right)$ and speed $\left(\mathrm{X}_{2}\right)$ on drug release after two hours $\left(\mathrm{Y}_{2}\right)$. 


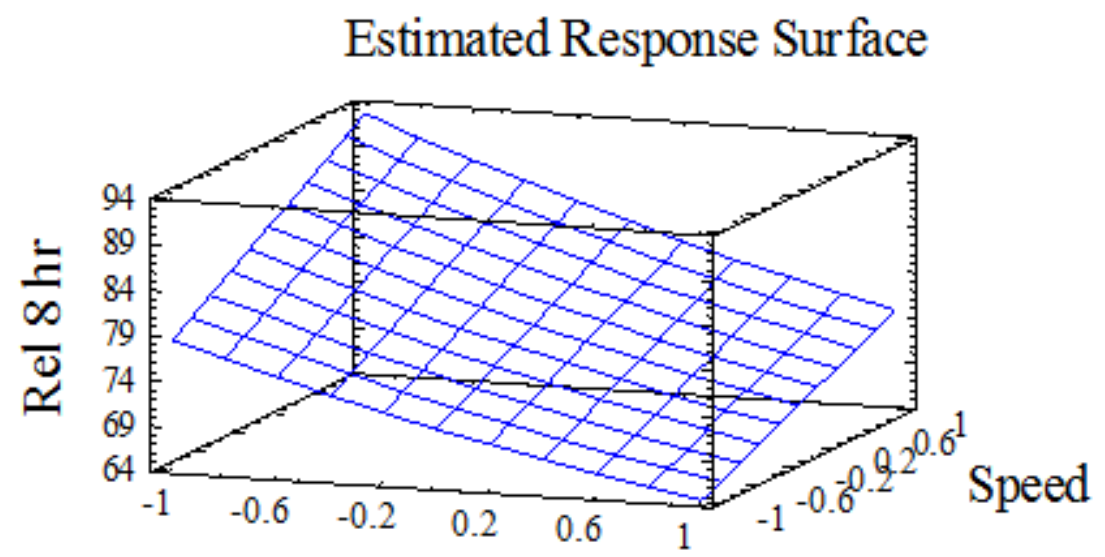

Drug Polymer Ratio

Figure (10) :Three dimensional contour plot for the effect of drug-polymer ratio $\left(\mathrm{X}_{1}\right)$ and speed $\left(\mathrm{X}_{2}\right)$ on drug release after eight hours $\left(\mathrm{Y}_{3}\right)$.

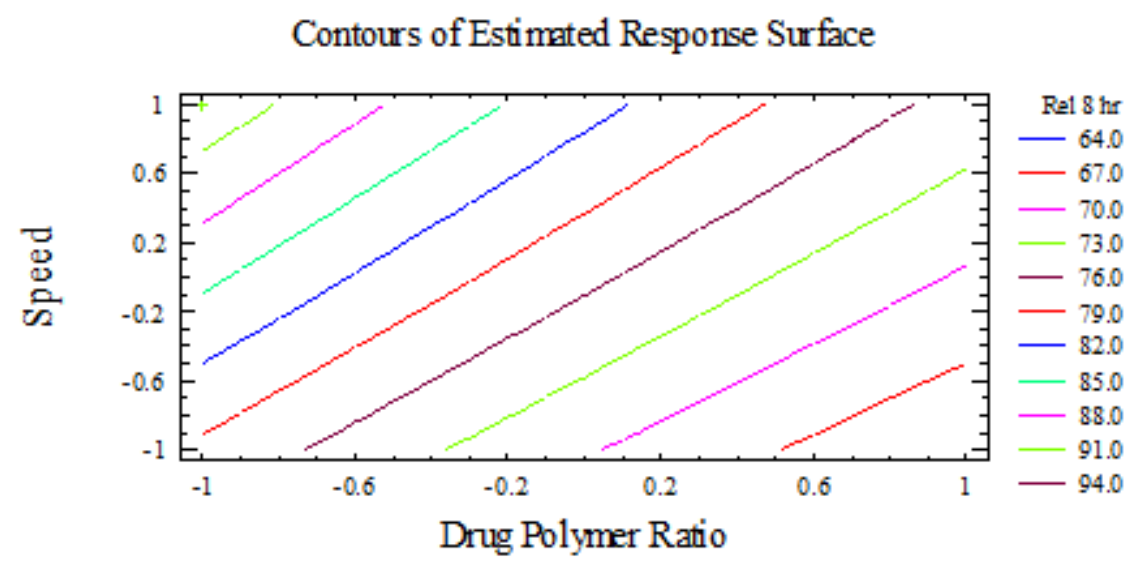

Figure (11) : Two dimensional contour plot for the effect of drug-polymer ratio $\left(\mathrm{X}_{1}\right)$ and speed $\left(\mathrm{X}_{2}\right)$ on drug release after eight hours $\left(\mathrm{Y}_{3}\right)$.

The release data of tolmetin sodium from ethyl cellulose microspheres prepared with different process variables were analyzed according to zero and first-order kinetics as well as, Higushi diffusion controlled mechanism Table (4). The release order of the drug was determined. It was found that the drug was released from the microspheres according to zero-order pattern, at different drugs to polymer ratios. The release medium dissolves the drug after penetrating the microcapsule wall by allowing the dissolved drug to diffuse out due to concentration gradient established between the interior of the microspheres and the release medium. 
Table (4): Analysis of the release data for tolmetin sodium microspheres prepared at different drug: polymer ratios of sodium alginate-ethyl cellulose mixture.

\begin{tabular}{|c|c|c|c|c|c|c|c|c|c|c|}
\hline \multicolumn{2}{|l|}{ Formula number } & F1 & F2 & F3 & F4 & F5 & F6 & F7 & F8 & F9 \\
\hline \multirow{2}{*}{ Zero-order } & $\mathbf{K}_{\mathbf{z}}$ & 8.148 & 10.50 & 7.108 & 8.837 & 8.781 & 9.482 & 6.44 & 5.215 & 9.323 \\
\hline & $\mathbf{R}_{\mathrm{z}}$ & $\underline{0.984}$ & $\underline{0.991}$ & $\underline{0.968}$ & $\underline{0.981}$ & $\underline{0.984}$ & $\underline{0.989}$ & 0.961 & $\underline{0.979}$ & $\underline{0.986}$ \\
\hline \multirow{2}{*}{ First-order } & 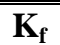 & 0.139 & 0.291 & 0.127 & 0.171 & 0.167 & 0.217 & 0.104 & 0.074 & 0.203 \\
\hline & $\mathbf{R}_{\mathrm{f}}$ & 0.962 & 0.942 & 0.952 & 0.960 & 0.958 & 0.966 & 0.948 & 0.946 & 0.963 \\
\hline \multirow{2}{*}{ Higuchi equation } & $\mathbf{K}_{\mathrm{h}}$ & 21.26 & 18.70 & 33.09 & 29.24 & 19.98 & 23.75 & 22.16 & 177.90 & 31.69 \\
\hline & $\mathbf{R}_{\mathrm{h}}$ & 0.924 & 0.990 & 0.967 & 0.976 & 0.971 & 0.985 & 0.960 & 0.976 & 0.976 \\
\hline
\end{tabular}

$\mathrm{K}_{\mathrm{z}}\left(\mathrm{mg} \cdot \mathrm{hr}^{-1}\right), \mathrm{K}_{\mathrm{f}}\left(\mathrm{hr}^{-1}\right)$ and $\mathrm{K}_{\mathrm{h}}\left(\mathrm{mg} / \mathrm{cm}^{2} \cdot \mathrm{hr}^{1 / 2}\right)$ are the release rate constants of zero-order, first order and Higuchi model kinetics, respectively, as well as $R_{\mathrm{z}}, \mathrm{R}_{\mathrm{f}}$ and $\mathrm{R}_{\mathrm{h}}$ are their corresponding correlation coefficients.

\section{CONCLUSION}

Coating the alginate microspheres with ethyl cellulose delayed the drug release at $\mathrm{pH}$ 7.4 by forming alginate-ethyl cellulose complex. The microspheres were spherical in shape with large pores at drug to polymer ratio 1:2 while at 1:4 drug to polymer ratio formed microspheres having smooth surface and small pores. The change in ethyl cellulose concentration had a non-significant effect on drug loading efficiency. Increasing the ethyl cellulose concentration decreased the drug release significantly. The increase in speed of rotation had significantly decreased drug loading efficiency, while it is significantly increased the drug release. Sodium alginate-ethyl cellulose microspheres followed zeroorder release kinetics. The behavior of the alginate-ethyl cellulose microspheres $\mathrm{pH} 7.4$ is of great interest for the delivery of non-steroidal anti-inflammatory drug into the small intestine.

\section{REFRENCES}

Alipour, S.; Montaseri, H. and Tafaghodi, M.(2010): Preparation and characterization of biodegradable paclitaxel loaded alginate microparticles for pulmonary delivery. Coll. Surfaces B: Biointerfaces, 81, 521-529.

Bipul,, N.; Lila, K. N; Bhaskar, M.B.; Pradeep, K.; Niraj, S. and Bhanu P. (2010): Int.J.Pharm.Res., 9 (2), 97-105.

Catarina, M. S.; Antonio, J.; Ribeiro B.; Isabel, V. F.; Alexandra, R. G. andFrancisco V.(2006):Alginate microspheres prepared by internal gelation: Development and effect on insulin stability. Int. J. of Pharm., 311, 1-10

Chan, L.W.; Lee, H.Y. and Heng, P.W.S (2002): Production of alginate microspheres by internal gelation using an emulsification method. Int. J. of Pharm., 242, 259-262.

Chen, L. and Subirade, M.( 2007): Effect of preparation conditions on the nutrient release properties of alginate/whey protein granular microspheres, Eur. J. of Pharm. and Biopharm, 65, 354-362.

Choi, B.Y.;Park, H.J.; Hwang, S.J., Park,J.P.(2002):Preparation of alginate beads for floating drug delivery system: effects of $\mathrm{CO} 2$ gas-forming agents. Int. J. Pharm., $239,81-91$. 
Giovanni,F.;Palmieri.,G., B.; Piera, D.M. and Sante, M.(2002):Microencapsulation of semisolid ketoprofen/polymer microspheres. Int. J. Pharm., 242,175-178 (2002).

Higuchi, T.(1963): Theoretical analysis of rate release of solid drugs dispersed in solid matrices. Pharm. Sci. 52, 1145-1149.

Jelvehgari, M.; Hassanzadeh, D. ; Kiafar, F.; Loveymi, D. and Amiri S.(2011): Preparation and Determination of Drug-Polymer Interaction and In-vitro Release of Mefenamic Acid Microspheres Made of CelluloseAcetate Phthalate and/or Ethylcellulose Polymers. Services. Iranian Journal of Pharmaceutical Research , 10, 457-467.

Jelvehgari, M.; Nokhodchi, A.; Rezapour, M.and Valizadeh,H.(2010): Effect of Formulation and Processing Variables on the Characteristics of Tolmetin Microspheres Prepared by Double Emulsion Solvent Diffusion Method. Indian J Pharm Sci. 2010 Jan-Feb; 72(1): 72-78

Karademir, S.; Oguz, D.; Senocak, F.; Ocal, B.; Karakurt, C. and Cabuk F(2003): Tolmetin and salicylate therapy in acute rheumatic fever: Comparison of clinical efficacy and side-effects. Pediatr Int., 45, 676-679.

Mahrous, G.M.; Ibrahim, M.A.; El-Badry, M. and Al-Anazi, F.K (2010): Indomethacin sustained release pellets prepared by extrusion/spheronization. J. Drug Deliv. Sci. Technol., 20, 119-125.

Perumal, D (2001): Microencapsulation of ibuprofen and Eudragit RS 100 by the emulsion solvent diffusion technique. Int. J. Pharm. 7, 1-11.

Singh, D.; Manju, S.; Swarnlata, S.; Dixit, V.K; and. Sara S(2010): Optimization and Characterization of Gentamicin Loaded Chitosan Microspheres for Effective Wound Healing. Indian J.Pharm. Educ. Res. 44(2), Apr-Jun.

Sudhamani, T.; Noveenkumar, K.; reddy,V.R.; Ravi, K., Revathi, R.and Ganesan, $V(2010)$ : Preparation and evaluation of ethyl cellulose microspheres of ibuprofen for sustained drug delivery. Int.J.Pharm.Res.Dev. 8, 119-125. 


\section{تصميم وتحسين خصائص الكريات الاقيقة المحضرة من عقار تولميتين الصوديوم بطريقة تكوين هلامات داخلية من المستحلب باستخدام طريقة رد الفعل السطحي}

$$
\text { محمود محمد احمد السيد }
$$

$$
\text { قسم الصيدلانيات والصبيلة الصناعية - كلية الصبدلة - جامعة الأزهر فرع اسيوط }
$$

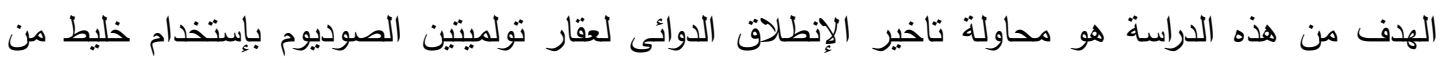

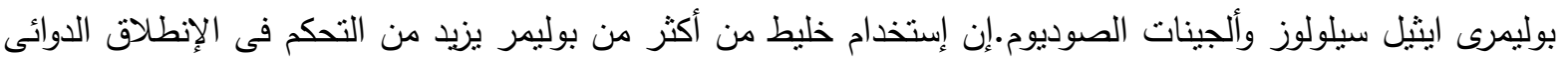

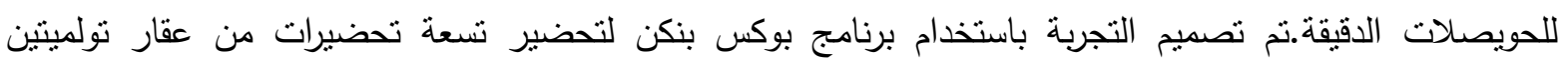

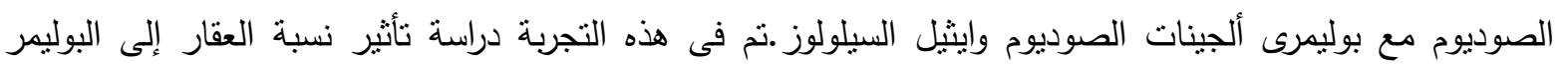

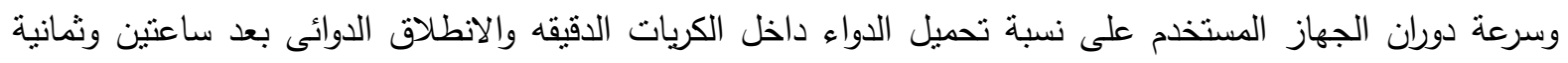
ساعات.وقد تم بنجاح تحضير حويصلات دقيقة من عقار تولميتين الصوديوم والمغطاة بولئيمرى الألجينات وايثيل

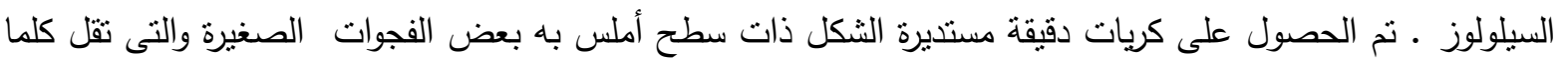

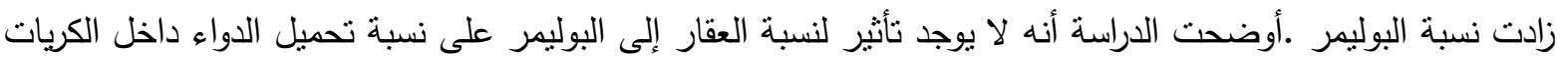

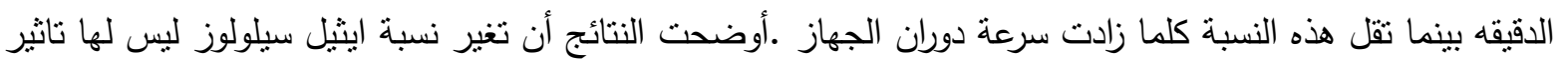

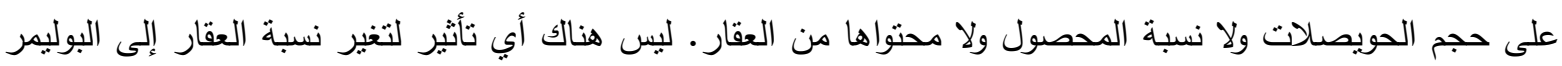

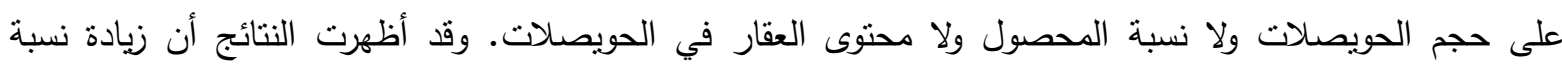

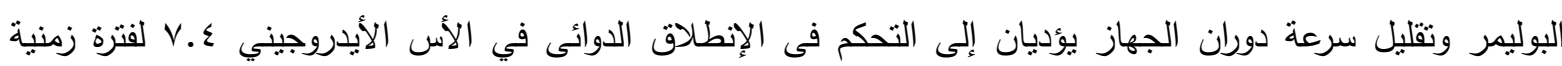

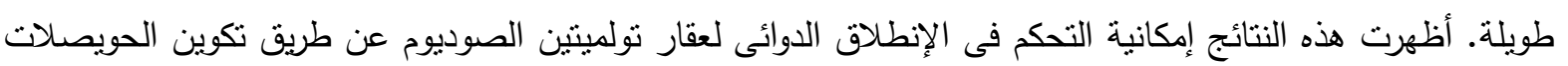

